\title{
Reutilization of Tacrolimus Extracted from Expired Prograf® Capsules: Physical, Chemical, and Pharmacological Assessment
}

\author{
Ziyad Binkhathlan, ${ }^{1,2,3}$ Mohamed M. Badran, ${ }^{1}$ Abdullah Alomrani, ${ }^{1}$ Ibrahim A. Aljuffali, ${ }^{1}$ \\ Mohammed Alghonaim, ${ }^{3}$ Saleh Al-Muhsen, ${ }^{4}$ Rabih Halwani, ${ }^{4}$ and Aws Alshamsan ${ }^{1,2,3,5}$
}

Received 7 July 2015; accepted 8 October 2015; published online 16 October 2015

\begin{abstract}
In this study, we investigated whether tacrolimus extracted and purified from the commercial capsules (Prograf ${ }^{\circledR} 5 \mathrm{mg}$ ) have retained its original quality and activity beyond the capsules expiration date in order to be reused for research purposes after extraction. High-performance liquid chromatography (HPLC) assay method was developed and validated for the quantification of tacrolimus, using cyclosporine A as an internal standard (IS). Moreover, a combination of analytical methods, including nuclear magnetic resonance (NMR), gas chromatography-mass spectrometry (GC-MS), Fourier transform-infrared (FT-IR) spectroscopy, X-ray diffraction (XRD), and differential scanning calorimetry (DSC) were used to assess the quality of extracted/purified tacrolimus. Suppression of murine peripheralblood mononuclear cells (PBMC) proliferation and the levels of interleukin-2 (IL-2) and interferon gamma (IFN- $\gamma$ ) were also assessed. The data obtained showed no detectable differences in the quality profile between the authentic sample and extracted drug. Also, the results showed that the extracted/ purified tacrolimus was able to suppress $\mathrm{T}$ cell proliferation, induced by concanavalin A, indicating the retained pharmacological activity. We proved that tacrolimus extracted/purified from expired Prograf ${ }^{\circledR}$ capsuled retains its purity and immunosuppressive activity and can be reused for research and possibly in pharmaceutical manufacturing.
\end{abstract}

KEY WORDS: extraction; immunosuppression; purity; tacrolimus; validation.

\section{INTRODUCTION}

Tacrolimus (Fig. 1a) is a potent immunosuppressive agent used clinically to reduce the risk of organ rejection in postoperative transplants patients (1). It is also used to treat different skin disorders such as atopic dermatitis (2), psoriasis (3), and vitiligo (4). Although both tacrolimus and cyclosporine A (CyA; Fig. 1b) inhibit $\mathrm{T}$ cell activation through calcineurin inhibition, each drug binds to a different target molecule. While CyA binds to cyclophilin, tacrolimus binds to FK506-binding protein (5). Clinical studies have shown that tacrolimus holds better safety and efficacy profiles compared to CyA (6). Consequently, tacrolimus is a

Electronic supplementary material The online version of this article (doi:10.1208/s12249-015-0433-7) contains supplementary material, which is available to authorized users.

\footnotetext{
${ }^{1}$ Nanomedicine Research Unit, Department of Pharmaceutics, King Saud University, P.O. Box 2457, Riyadh, 11451, Saudi Arabia.

${ }^{2}$ King Abdullah Institute for Nanotechnology, King Saud University, Riyadh, Saudi Arabia.

${ }^{3}$ King Salman Bin Abdulaziz Chair for Kidney Disease, King Saud University, Riyadh, Saudi Arabia.

${ }^{4}$ Prince Naif Center for Immunology Research, King Saud University, Riyadh, Saudi Arabia.

${ }^{5}$ To whom correspondence should be addressed. (e-mail: aalshamsan@ksu.edu.sa)
}

relatively expensive molecule since the average cost of $5 \mathrm{mg}$ of tacrolimus monohydrate is EUR 256.00 (USD 288.60) (7).

Tons of expensive medications are being disposed annually because they passed their expiration date although the printed expiration date may not necessarily represent the ultimate shelf life $(8,9)$. The main purpose of this study is to investigate whether tacrolimus, extracted from expired commercial Prograf ${ }^{\circledR}$ capsules $(5 \mathrm{mg})$, retains purity and pharmacological activity. For this purpose, a highperformance liquid chromatography (HPLC) assay method was developed and validated for the quantification of tacrolimus, using cyclosporine $\mathrm{A}$ as an internal standard (IS). Moreover, a combination of analytical methods, including, nuclear magnetic resonance (NMR), gas chromatographymass spectrometry (GC-MS), X-ray diffraction (XRD), Fourier transform infrared spectroscopy (FT-IR), and differential scanning calorimetry (DSC) were used to assess the quality of tacrolimus. Lymphocyte proliferation assay of mouse peripheral-blood mononuclear cells (PBMCs) and enzyme-linked immunosorbent assay (ELISA) to determine the levels of interleukin-2 (IL-2) and interferon gamma $(\mathrm{IFN}-\gamma)$ was also performed to further assess the pharmacological activity of the extracted drug. These tests assessed the purity and activity of tacrolimus extracted from Prograf $₫$ capsules beyond their expiration date. 
a

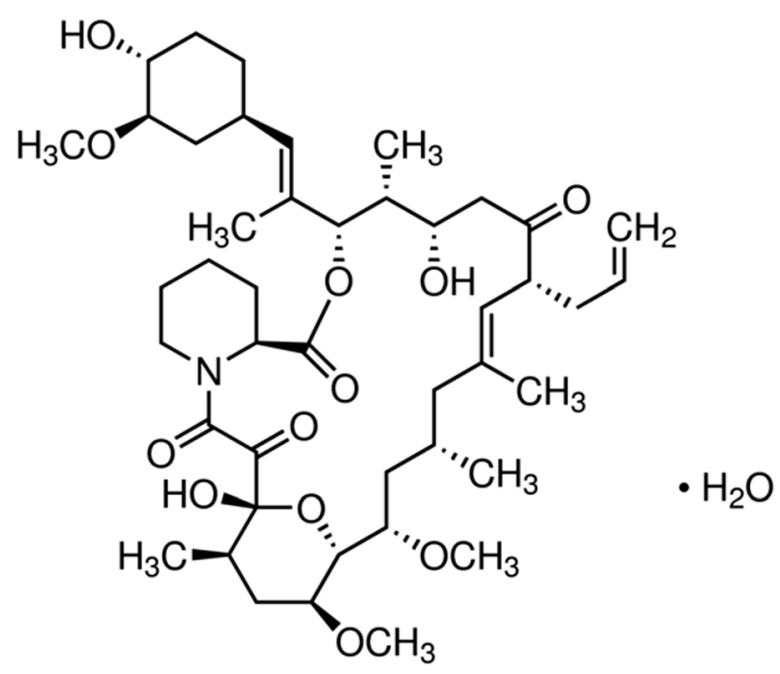

b

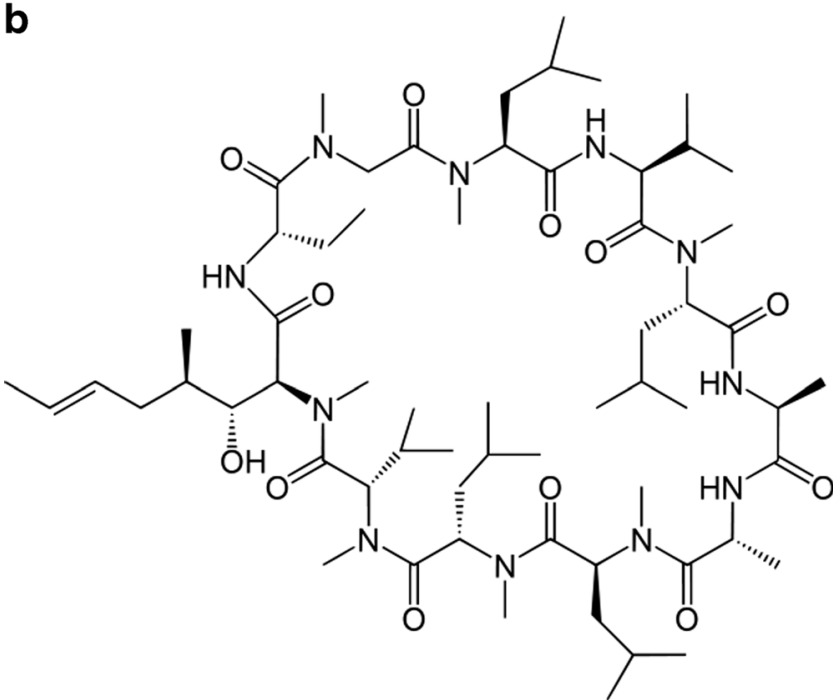

Fig. 1. Chemical structures of a tacrolimus monohydrate and $\mathbf{b}$ cyclosporine A (IS). Structures were reprinted with permission from www.sigmaaldrich.com

\section{MATERIALS AND METHODS}

\section{Materials}

Tacrolimus reference standard (FK-506 monohydrate $\geq 98 \%$ (HPLC)), cyclosporine A, carboxyfluorescein diacetate succinimidyl ester (CFSE) and concanavalin A (ConA) were purchased from Sigma (TX, USA). Acetonitrile (HPLC grade) was supplied by Fisher Scientific Co. (Leicestershire LE/15 RG, UK). 2-Propanol (HPLC grade) was supplied by PANREAC Quimica SA Co. (Barcelona, Spain). Anti-mouse CD4-APC and CD8-PE-CY7 were purchased from R\&D systems (MN, USA). Dulbecco's modified Eagle's medium (DMEM), fetal bovine serum (FBS), penicillin, and streptomycin were purchased from Gibco ${ }^{\circledR}$, Life Technologies (CA, USA). IFN- $\gamma$ and IL-2 Platinum ELISA kits were purchased from Affymetrix ${ }^{\circledR}$ eBioscience (CA, USA). Deionized water was prepared in-house using Millipore system. Prograf ${ }^{\circledR}$ capsules (batch \# 7241, expiry date 06/2010; batch \# 4104, expiry date 08/2012; and batch \# 6875, expiry date 04/2015) were kindly provided by King Khalid University Hospital Pharmacy, King Saud University, Riyadh, Saudi Arabia. Non-expired Prograf ${ }^{\circledR}$ capsules (batch \# 9311, expiry date 08/2017) were purchased from Hikma Pharmaceuticals, Riyadh, Saudi Arabia. BALB/c mice were kindly provided by the College of Pharmacy Animal House, King Saud University, Riyadh, Saudi Arabia.

\section{Methods}

\section{Tacrolimus Capsule Content Measurement}

To determine the amount of tacrolimus in capsules or extract, a previously reported colorimetric assay based on sulfuric acid reaction was used (10) with minor modification. Briefly, the contents of $5 \mathrm{mg}$ tacrolimus expired capsules or extract were dissolved in $1 \mathrm{~mL}$ ethanol. The mixture was then vigorously vortexed and subjected to centrifugation at $20,000 \times g$ for $15 \mathrm{~min}$ at $4^{\circ} \mathrm{C}$. The supernatants were diluted 20 -fold in acetonitrile. Aliquots of tacrolimus solution (0$100 \mu \mathrm{L}$ ) were transferred to $4-\mathrm{mL}$ glass vials, $40 \mu \mathrm{L}$ of sulfuric acid was added, and the mixture was diluted to $1 \mathrm{~mL}$ with acetonitrile. Samples $(400 \mu \mathrm{L})$ were transferred to UV cuvette and measured at $295 \mathrm{~nm}$ against a solvent blank. The percent mean active ingredient in expired Prograf $®$ capsules or extract was compared with non-expired Prograf ${ }^{\circledR}$ capsules.

\section{Extraction of Tacrolimus from Prograf® Capsules}

The powder of Prograf $®$ capsules was extracted with ethyl acetate $(150 \mathrm{~mL} \times 4)$ by using a shaking water bath (GFL, Burgwedel, Germany) at a temperature of $40^{\circ} \mathrm{C}$ for $30 \mathrm{~min}$. The extraction with ethyl acetate was repeated four times. The combined ethyl acetate extracts were dried by sodium sulfate, filtered and evaporated to dryness by using a rotary evaporator (Buchi, Flawil, Switzerland) at $40^{\circ} \mathrm{C}$.

\section{Purification and Isolation of Tacrolimus}

The ethyl acetate extract was subjected to column chromatography $(2.0 \times 60 \mathrm{~cm})$ on a pre-packed silica gel column (80 g silica gel 60 F254, Merck, Germany). The elution was performed with a gradient of chloroform-methanol $(90: 10)$ to pure methanol $(v / v)$. Fractions were pooled into major fractions based on their thin-layer chromatography profiles (TLC, silica gel 60 F254, Merck, Germany) compared with tacrolimus standard. TLC analysis of the fractions with vanillin/ sulfuric acid $(2 \%)$ and heating at $100^{\circ} \mathrm{C}$, allowed the constitution of four fractions. The tacrolimus subfraction was further purified by using chromatotron (Harrison Research, USA) (silica gel 60 F254, layer thickness 2 mm, Merck, Germany). The elution was performed with a mobile phase composed of chloroform-methanol $(98: 2, v / v)$. The TLC analysis with an elution system of chloroform-methanol (90:10) showed a pure violet spot with $R_{\mathrm{f}}$ value of 0.61 which was attributed to tacrolimus. 


\section{NMR Spectroscopy}

${ }^{1} \mathrm{H}$ NMR analysis was performed with a Bruker Ultra shield $500.133 \mathrm{MHz}$ spectrometer in pyridine-d5 with TMS as internal standard. Baseline correction, calibration, and processing were performed using Topspin software.

\section{$G C-M S / M S$}

Analyses were conducted directly at a mass spectrometer (Varian 320 TQMS). The sample corresponding to a powder particle of tacrolimus was put in direct probe and introduced into the mass spectrometer directly starting from temperature 10 to $450^{\circ} \mathrm{C}$ at the rate of $10^{\circ} \mathrm{C} / \mathrm{min}$. Electron ionization of the mass spectrometer operated at the ionization energy of $70 \mathrm{eV}$, temperature of the ion source of $200^{\circ} \mathrm{C}$, and the transfer line temperature is at $150^{\circ} \mathrm{C}$. The mass range in direct probe is set at the range of mass of $m / z$ 25-900.

\section{X-ray Diffractometery}

X-ray diffractometer was used to study the crystallinity state of the extracted tacrolimus. Tacroliums powder sample was loaded in the XRD instrument (automated Rigaku Ultima IV). The X-ray diffractogram of the investigated sample was collected using $2 \theta$ scan axis mode, scan speed set at $0.5 \%$ min, and covering scan range of $3.0-60.0^{\circ}$. The scanning process was performed at room temperature.

\section{FT-IR Spectroscopy}

The FT-IR spectrum of the extracted tacrolimus was obtained using an FT-IR spectrophotometer (PerkinElmer, USA). Tacrolimus sample was ground with potassium bromide (spectroscopic grade) and compressed into a thin disk using hydraulic press before scanning from 4000 to $600 \mathrm{~cm}^{-1}$.

\section{Differential Scanning Calorimetry}

Thermogram of the extracted tacrolimus was obtained using differential scanning calorimetry (DSC-60, Shimadzu, Japan). Tacrolimus sample (3-5 mg) was loaded in an aluminum pan and sealed with aluminum lids by a crimper. The sample then thermally scanned against an empty aluminum pan with lid, at a heating rate of $10^{\circ} \mathrm{C} / \mathrm{min}$, covering temperature range of $25-200^{\circ} \mathrm{C}$. Nitrogen purging at $40 \mathrm{~mL} / \mathrm{min}$ was used during scanning. The TA-60WS thermal analysis software was used to calculate the thermal parameters of the scanned sample.

\section{Chromatographic Apparatus and Conditions}

Tacrolimus was determined using a reverse-HPLC method. The HPLC system (Waters ${ }^{\mathrm{TM}} 1500$ series controller, USA) equipped with wavelength detector (Waters ${ }^{\mathrm{TM}} 2489$ a Dual ${ }^{\mathrm{TM}}$ Absorbance detector, USA), pump (Waters ${ }^{\mathrm{TM}} 1525$ a Binary pump, USA), an automated sampling system (Waters ${ }^{\mathrm{TM}} 2707$ Plus Autosampler, USA). The HPLC system was monitored by "Breeze (Waters ${ }^{\mathrm{TM}}$ )" software. Tacrolimus was analyzed by injecting $100 \mu \mathrm{L}$ of drug solution using a mobile phase consisted of acetonitrile:deionized water:isopropyl alcohol (60:30:10v/v) adjusted to $\mathrm{pH}$ of 3 by phosphoric acid and pumped through a reversed-phase $\mathrm{C}_{18}$ column (MachereyNagel, $4.6 \times 150 \mathrm{~mm}, 10-\mu \mathrm{m}$ particle size) at a flow rate of $1.0 \mathrm{~mL} / \mathrm{min}$. Tacrolimus concentration was detected using UV detector adjusted at $215 \mathrm{~nm}$. The column temperature was adjusted at $60^{\circ} \mathrm{C}$.

\section{Standard and Stock Solutions}

Stock solutions of tacrolimus ( $1 \mathrm{mg} / \mathrm{mL})$ and cyclosporin A $(1 \mathrm{mg} / \mathrm{mL})$ as an internal standard (IS) were prepared in acetonitrile. These stock solutions were stored at $-20^{\circ} \mathrm{C}$ in the dark. Each day, working solutions of tacrolimus $(20 \mu \mathrm{g} / \mathrm{mL})$ and IS $(100 \mu \mathrm{g} / \mathrm{mL})$ were freshly prepared before analysis. Set of calibrating standards at 100, 200, 500, 2500, 1000, 5000, and $10,000 \mathrm{ng} / \mathrm{mL}$ of tacrolimus, each containing $5 \mu \mathrm{g} / \mathrm{mL}$ of IS. Three concentrations of tacrolimus $(100,1000$, and 10,000 ng/ $\mathrm{mL}$ ) were chosen from calibration curve points as quality control samples (QCs).

\section{Validation of the Assay Method}

The method was validated according to the US Food and Drug Administration (FDA) guidelines for bioanalytical method validation (11). Linearity of the assay method was determined by repeated assay of six standard curves on six separate days. The three points of QC samples were analyzed thrice with each standard curve. A linear regression was obtained by plotting the peak area ratio of the drug to IS versus drug concentration. The best weighting factor for linear regression was determined according to the results and to the variation of variance with respect to concentration, which was found to be $1 /$ concentration. Intra- and inter-day precision (coefficient of variation $(\mathrm{CV} \%)$ ) and accuracy (expressed as bias\%) were evaluated using three points of QC samples. Six replicates of each point were assayed in one run for the intraday experiment. Three replicates of each point of QC samples were assayed every day for six different days (inter-day experiment). According to FDA guidelines, the accuracy and imprecision for all tested concentrations should be within $\pm 15 \%$ with the exception of the lower limit of quantification (LLOQ) sample, in which these parameters should not exceed $20 \%$.

\section{T Cell Proliferation}

Peripheral blood mononuclear cells (PBMCs) were isolated from pooled whole blood samples of five mice $(1.5 \mathrm{~mL} /$ mice) using Ficoll density gradient centrifugation. PBMCs were incubated with pre-warmed PBS containing carboxyfluorescein diacetate succinimidyl ester (CFSE) dye $(2 \mu \mathrm{M})$ for $8 \mathrm{~min}$ at $37^{\circ} \mathrm{C}$. Cells were washed with PBS and treated with extracted tacrolimus at a concentration of $25 \mathrm{ng} / \mathrm{mL}$ for $2 \mathrm{~h}$ as described in (12). Thereafter, cells were washed with PBS and subsequently stimulated with ConA super antigen $(10 \mu \mathrm{g} / \mathrm{mL} /$ $10^{6}$ cells). The cells were then incubated for 4 days at $37^{\circ} \mathrm{C}$. Standard surface staining protocol was followed for $\mathrm{CD} 4^{+}$and $\mathrm{CD}^{+} \mathrm{T}$ cells using anti-mouse CD4-APC and CD8-PE-CY7 monoclonal antibodies. Frequency of proliferative lymphocytes was determined using flow cytometry (LSRII BD biosciences) by acquiring up to $10^{6}$ events for each condition. 
Data were then analyzed using DIVA software (BD Biosciences). The animal studies were performed based on protocols approved by The Experimental Animal Care Center Review Board, College of Pharmacy, King Saud University (no. C.P.R.-3526).

\section{ELISA}

Mice PBMCs were isolated and suspended in complete DMEM media containing $10 \%$ gamma-irradiated FBS, 10 units $/ \mathrm{mL}$ penicillin, and $10 \mu \mathrm{g} / \mathrm{mL}$ streptomycin at $37^{\circ} \mathrm{C}$. Cells were treated as described earlier and then incubated at $37^{\circ} \mathrm{C}$ for $48 \mathrm{~h}$. Supernatants were collected at 0,24 , and $48 \mathrm{~h}$ and IFN- $\gamma$ and IL- 2 levels were determined according to the manufacturer instructions.

\section{Statistical Data Analysis}

Data were analyzed for statistical significance $(p<0.05)$ by Student's $t$ test (SPSS for Windows, Version 16.0). Where indicated, the results were summarized as mean \pm SD.

\section{RESULTS}

\section{Extraction and Purification of Tacrolimus from Prograf ${ }^{\circledR}$ Capsules}

Table I lists the average percent active ingredient (tacrolimus) in extracted drug from expired capsules (batch \#7241; expiry 06/2010) compared with Prograf®. The experiment was performed in August 2014. The calculated extraction recovery of drug from expired and non-expired capsules were 85.9 and $90.4 \%$, respectively. Table II lists the percent mean tacrolimus content in different batches of expired Prograf $®$ capsules. The experiment was performed in September 2015. Prograf ${ }^{\circledR}$ batches \#7241 and \#4104 were indeed expired since the percent mean content of tacrolimus was less than $90 \%$. Interestingly, however, the percent mean content of tacrolimus in batch \# 6875 was found to be higher than $93 \%$ (range 91-99\%). Although it is more than 4 months past the printed expiry date, it still has over $93 \%$ of the label claim. Tacrolimus was successfully extracted/purified from expired Prograf® capsules as confirmed by TLC analysis (Figure S1). The method used for extraction/purification was associated with high purity and yield as confirmed by HPLC and spectrophotometric analyses (discussed below).

\section{Characterization of Extracted/Purified Tacrolimus}

Figure 2 shows an overlay of NMR spectrum of authentic and extracted tacrolimus. By examination of the spectra, they clearly show identical signals, which are also comparable to the previously published NMR data (13). Beside the molecular ion of tacrolimus $(\mathrm{m} / \mathrm{z}$ 804.3), five main degradation products were obtained. The identified fragments were: $m / z, 142\left(\mathrm{C}_{8} \mathrm{H}_{14} \mathrm{O}_{2}\right), m / z, 168\left(\mathrm{C}_{11} \mathrm{H}_{20} \mathrm{O}\right)$, $m / z 227\left(\mathrm{C}_{11} \mathrm{H}_{17} \mathrm{NO}_{4}\right), \mathrm{m} / z, 238\left(\mathrm{C}_{15} \mathrm{H}_{26} \mathrm{O}_{2}\right)$, and $\mathrm{m} / z .278$ $\left(\mathrm{C}_{19} \mathrm{H}_{18} \mathrm{O}_{2}\right)$, which are identical to those reported by $\mathrm{B}$ er et al. (14). The X-ray diffractogram of the extracted tacrolimus (Fig. 3) reveals clear diffraction peaks at 5-30 $2 \theta^{\circ}$. This profile reflects a high degree of crystallinity (15). Figure S2 shows the FT-IR spectrum of the extracted drug. All the major absorption bands associated with tacrolimus molecule are present, namely, $3461.50 \mathrm{~cm}^{-1}(\mathrm{O}-$ $\mathrm{H}), 3080 \mathrm{~cm}^{-1}(\mathrm{CH}=), 2826.70-2936.21 \mathrm{~cm}^{-1}(\mathrm{C}-\mathrm{H})$, $1741.66 \mathrm{~cm}^{-1}(\mathrm{C}=\mathrm{O}), 1724.10 \mathrm{~cm}^{-1}(\mathrm{C}=\mathrm{O}), 1694.60 \mathrm{~cm}^{-1}$ $(\mathrm{C}=\mathrm{O})$, and $1640.38 \mathrm{~cm}^{-1}(\mathrm{C}=\mathrm{C})$. Moreover, the spectrum also shows an identical fingerprint of tacrolimus compared to reference IR spectrum. DSC profile of the extracted tacrolimus (Fig. 4) shows a broad endothermic peak stretched from 49 to $100^{\circ} \mathrm{C}$, which could be attributed to the solvent evaporation, followed by a significant endothermic peak at $126^{\circ} \mathrm{C}$, which is the melting point reported for tacrolimus in DrugBank database (http:// www.drugbank.ca/drugs/DB00864).

\section{HPLC Analysis Validation}

At the beginning, a number of mobile phases composed of acetonitrile, methanol, and water at different ratios were tested. Best results were obtained when an isocratic acetonitrile:water:isopropyl alcohol (60:30:10) mobile phase was used. The addition of isopropyl alcohol and adjustment of the $\mathrm{pH}$ at 3 resulted in sharper peaks and shorter retention times for tacrolimus as well as cyclosporine A (IS). Tacrolimus and the IS were well separated with retention times of around 5.3 and $10.5 \mathrm{~min}$, respectively. The linearity of the calibration curve was evaluated by seven-point standards; covering a

Table I. Comparison of Tacrolimus Recovery from Expired Prograf ${ }^{\circledR}$ Capsules (Batch \# 7241) and Extracted Drug Measured as a Percent of Non-Expired Prograf®

\begin{tabular}{|c|c|c|c|c|c|}
\hline Tacrolimus source & Mean \% tacrolimus & $N$ (assays) & $\mathrm{SD}$ & $\mathrm{CV} \%$ & Range \% tacrolimus \\
\hline Prograf® (non-expired) & 100 & 7 & 5.9 & 5.9 & 94-109 \\
\hline Prograf® (expired) & 89.1 & 5 & 3.2 & 3.6 & $82-93$ \\
\hline Extracted tacrolimus (from non-expired caps) & 90.4 & 4 & 4.2 & 4.7 & $85-94$ \\
\hline Extracted tacrolimus (from expired caps) & 85.9 & 4 & 1.5 & 1.7 & $83-88$ \\
\hline
\end{tabular}

The experiment was performed in August 2014. The percent mean active ingredient in expired Prograf® capsules or extract was compared with non-expired Prograf ${ }^{\circledR}$ capsules determined by a colorimetric assay

$N$ number, $S D$ standard deviation, $C V \%$ coefficient of variation 
Table II. Comparison of Tacrolimus Recovery from Different Batches of Expired Prograf ${ }^{\circledR}$ Capsules Measured as a Percent of Non-Expired Prograf®

\begin{tabular}{llllll}
\hline Tacrolimus source & Mean \% tacrolimus & $N$ (assays) & SD & CV\% & Range \% tacrolimus \\
\hline Prograf® (non-expired) & 100 & 3 & 5.1 & 5.1 & $97-106$ \\
Batch \#6875 (expiry 4/2015) & 93.8 & 3 & 2.2 & 2.4 & $91-99$ \\
Batch \#4104 (expiry 8/2012) & 88.3 & 3 & 3.4 & 3.9 & $81-99$ \\
Batch \#7241 (expiry 6/2010) & 85.2 & 3 & 2.5 & 3.0 & $82-91$ \\
\hline
\end{tabular}

The experiment was performed in September 2015. The percent mean active ingredient in different batches of expired Prograf ${ }^{\circledR}$ capsules was compared with non-expired Prograf® capsules determined by a colorimetric assay

$N$ number, $S D$ standard deviation, $C V \%$ coefficient of variation

concentration range of $(0.1-10 \mu \mathrm{g} / \mathrm{mL})$ of tacrolimus, each calibration curve was evaluated six times. The linear regression of the calibration curves produced a mean slope and intercept of 0.00008 and 0.0032 , respectively, with correlation coefficient $\left(R^{2}\right)$ of 0.9996 . The assay CV\% for both intra-day and inter-day assessments was less than $12 \%$ including the lowest concentration used in the calibration and validation samples $(0.1 \mu \mathrm{g} / \mathrm{mL})$. Mean error was less than $5 \%$ in all the concentrations over $0.1 \mu \mathrm{g} / \mathrm{mL}$ (Table III). The low variability in the validation data demonstrated the accuracy and reproducibility of the developed method. The method's lower limit of quantitation (LLOQ), i.e., the minimum level at which tacrolimus could be detected with acceptable accuracy and precision, was set at $0.1 \mu \mathrm{g} / \mathrm{mL}$. The purity of extracted tacrolimus was assessed by comparing the average peak area obtained from $5 \mu \mathrm{g} / \mathrm{mL}$ sample of the extract with that of standard tacrolimus. The purity of the extract was estimated to be $\sim 83.6 \%$.

\section{Pharmacological Assessment of Extracted/Purified Tacrolimus}

To test the bioactivity of extracted tacrolimus, $\mathrm{T}$ cell proliferation assay was performed. As shown in Fig. 5, the ConA-induced proliferation of $\mathrm{CD}^{+} \mathrm{T}$ cells (Fig. 5a) and $\mathrm{CD}^{+} \mathrm{T}$ cells (Fig. 5b) was dramatically suppressed in response to pre-incubation with the extracted/purified tacrolimus. The suppressive effect was demonstrated by $\sim 2.5$-fold and 1.5-fold decrease in the proliferation of $\mathrm{CD}^{+} \mathrm{T}$ cells and $\mathrm{CD}^{+} \mathrm{T}$ cells, respectively. Similarly, suppression of IL-2 secretion in $\mathrm{T}$ cell culture supernatants was determined as another indicator of proliferation (Fig. 6). Although IL-2 levels were increasing in a timely
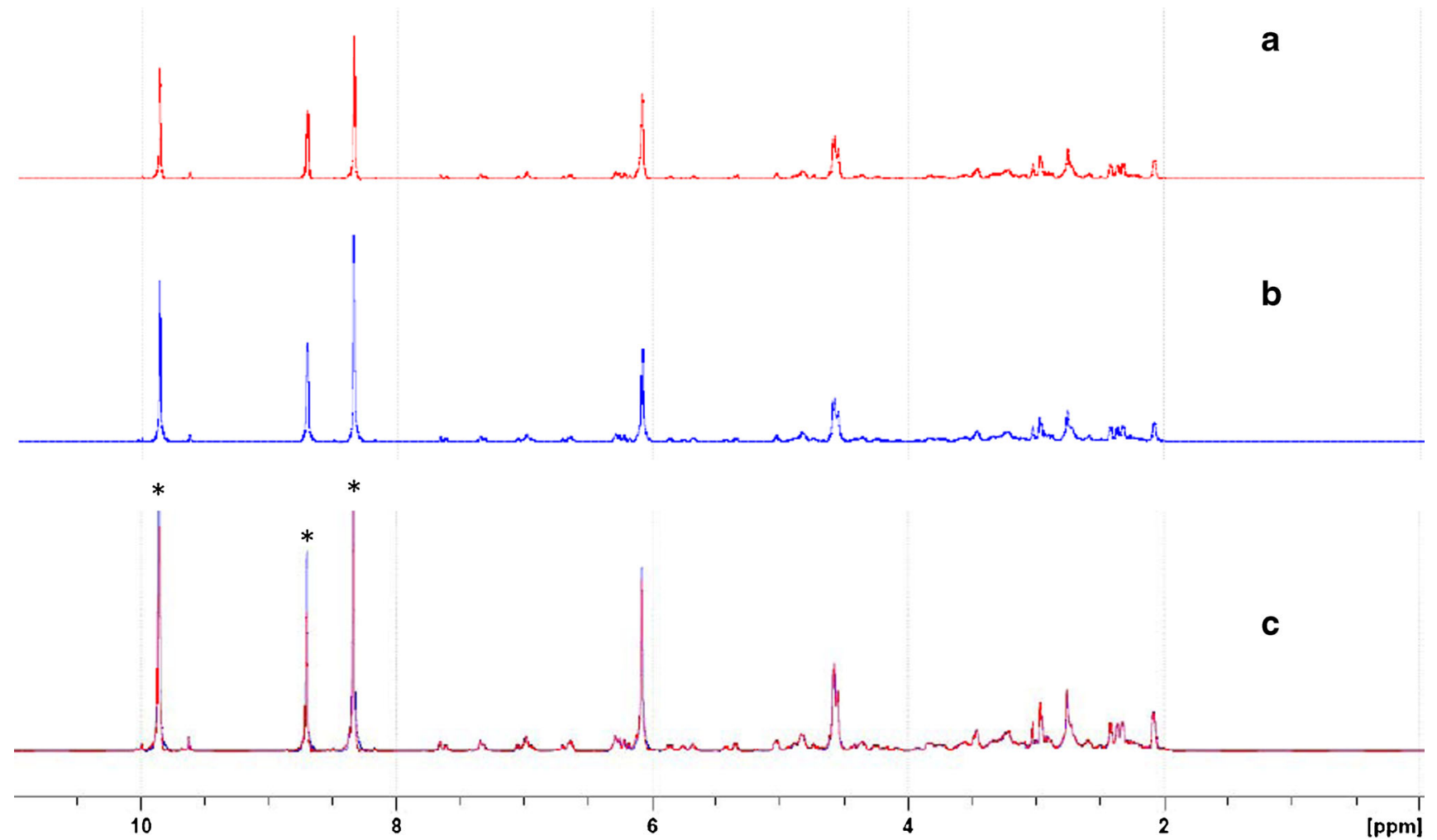

Fig. 2. The 0-11 ppm region of the $500 \mathrm{MHz}{ }^{1} \mathrm{H}$ NMR spectrum of a extracted tacrolimus, b reference standard, and $\mathbf{c}$ an overlay of (a) and (b). Protonated pyridine signals are marked with asterisks. The spectra of the reference standard and the extracted tacrolimus are identical 


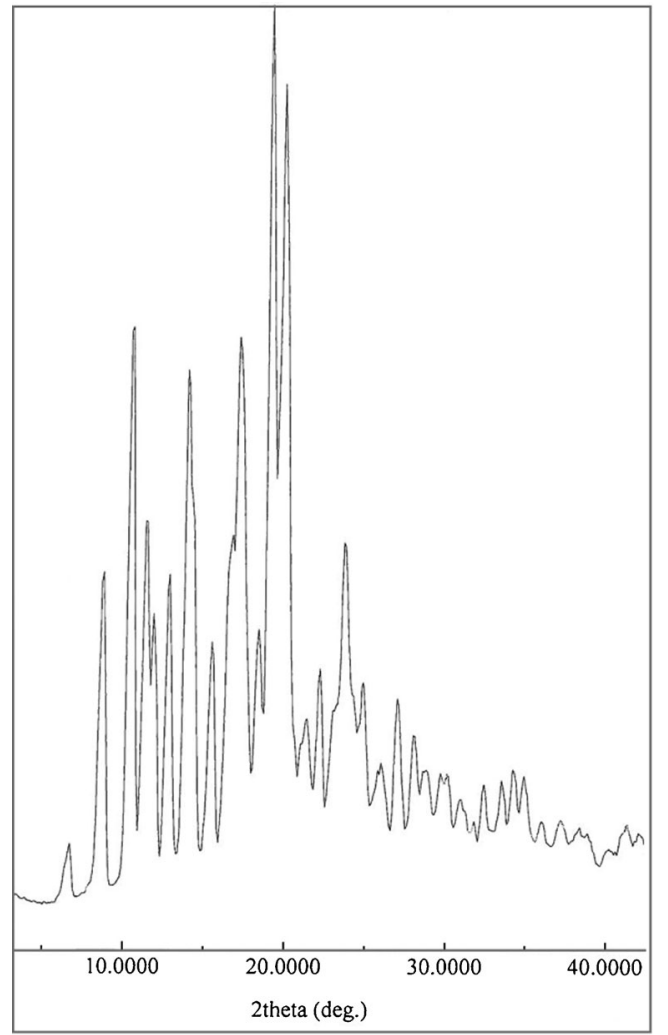

Fig. 3. XRD spectrum of extracted tacrolimus showing numerous sharp peaks at different diffraction angle indicating its crystalline nature. The diffractogram was collected using $2 \theta$ scan axis mode, scan speed set at $0.5^{\circ} \mathrm{min}$, and covering scan range of $3.0-60.0^{\circ}$. The scanning process was performed at room temperature

fashion upon ConA stimulation in both tacrolimus-treated and untreated groups, pre-incubation with the extracted/ purified tacrolimus has successfully suppressed $\mathrm{T}$ cell proliferation by $\sim 4.2$ folds. As IL- 2 is upregulated in proliferating $\mathrm{T}$ cells (discussed below), the reduced levels of IL2 tacrolimus-treated group is consistent with its suppressive effect on $\mathrm{T}$ cell proliferation shown in (Fig. 5). Furthermore, IFN- $\gamma$ levels were also determined. Figure 7 shows a significant suppression of IFN- $\gamma$ secretion the

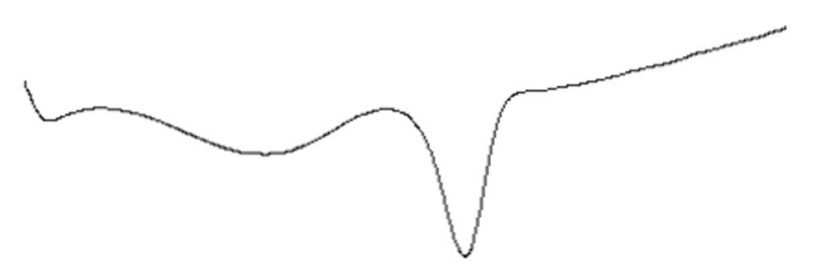

$\begin{array}{cccc}50.0 & 100.0 & 150.0 & 200.0 \\ & \text { Temperature }\left({ }^{\circ} \mathrm{C}\right) & \end{array}$

Fig. 4. DSC profile of extracted tacrolimus showing the characteristic endothermic peak at $126^{\circ} \mathrm{C}$, with corresponds to the melting point of tacrolimus. The sample were thermally scanned against an empty aluminum pan with lid, at heating rate of $10^{\circ} \mathrm{C} / \mathrm{min}$, covering temperature range of $25-200^{\circ} \mathrm{C}$ group pre-incubated with the extracted/purified tacrolimus where IFN- $\gamma$ levels were $\sim 22$ folds less than the untreated counterparts.

\section{DISCUSSION}

The main purpose of this study was to investigate the possibility of reusing tacrolimus, the active ingredient, from expired Prograf $\AA$ capsules. Multiple physical, chemical, and biological analyses were employed to assess the quality, purity, and pharmacological activity of the active pharmaceutical ingredient (API) following extraction and purification. The suitable selection of the chromatographic fractions eluted from silica gel column was determined by means of a TLC analysis. The purity was further confirmed by validated HPLC assay against tacrolimus standard. The chromatograms of the extracted drug and the reference standard both showed a single peak with a retention time of $\sim 5 \mathrm{~min}$. The purity of the extract was estimated to be $83.6 \%$. This is very close to the value estimated from the colorimetric assay, which was $85.9 \%$. The recovery of tacrolimus following extraction from nonexpired and expired capsules was 90.4 and $85.9 \%$, respectively, which indicates a high purity and yield of extract (Table I). The percent mean tacrolimus content in two batches of the expired capsules used in this study was found to be less than $90 \%$, which confirms that the capsules are expired (Table II). The percent mean content of tacrolimus in the third batch used in current study was found to be higher than $93 \%$ (range 91-99\%). Bearing in mind that the shelf life of the marketed drug (Prograf $®$ ) is only 3 years, and knowing that the analysis of capsule content was performed in September 2015, i.e., more than 4 months past the printed expiry date, this indicates that 3 years is probably a conservative period.

Several NMR studies for structure determination and synthesis of tacrolimus were performed by several groups, e.g., Nakatsuka et al. (16) and Mierke et al. (17) in the early 1990s. In these studies, tacrolimus was dissolved in deuterated chloroform and methanol due to the limited aqueous solubility of tacrolimus. In 2012, Ferraboschi et al. (13) have shown that using deuterated pyridine as a solvent for tacrolimus enhanced the resolution of proton resonances for tacrolimus API and related impurities compared to methanol or chloroform. Therefore, deuterated pyridine was used in the current study for the NMR analysis of tacrolimus. As shown in Fig. 2, there was no detectable difference between the reference sample and the extracted drug.

Recently, B er et al. (14) performed a characterization study for tacrolimus raw material using thermal analysis and pyrolysis coupled to GC-MS. They studied the thermal decomposition of tacrolimus at two different temperatures 300 and $400^{\circ} \mathrm{C}$. Under the conditions reported by B er et al., the molecular ion of tacrolimus $(\mathrm{m} / \mathrm{z}, 804)$ was not detected. Nonetheless, five main degradation products were obtained. The identified fragments were as follows: $m / z, 142\left(\mathrm{C}_{8} \mathrm{H}_{14} \mathrm{O}_{2}\right), m / z$ $168\left(\mathrm{C}_{11} \mathrm{H}_{20} \mathrm{O}\right), m / z, 227\left(\mathrm{C}_{11} \mathrm{H}_{17} \mathrm{NO}_{4}\right), m / z, 238\left(\mathrm{C}_{15} \mathrm{H}_{26} \mathrm{O}_{2}\right)$, and $m / z, 278\left(\mathrm{C}_{19} \mathrm{H}_{18} \mathrm{O}_{2}\right)$ (14). In our study, the five main degradation fragments reported in $\mathrm{B}$ er et al. study were obtained. Interestingly, under the conditions used in the current study, the molecular ion of tacrolimus $(\mathrm{m} / \mathrm{z}$ 804.3) was also 
Table III. Intra-day and Inter-day Precision and Accuracy of Tacrolimus (in Acetonitrile) Determination by the Developed HPLC Assay

\begin{tabular}{lll}
\hline Nominal Conc. $(\mathrm{ng} / \mathrm{mL})$ & Bias $(\%)$ & Precision $(\%)$ \\
\hline Intra-day $(n=6)$ & & 15.8 \\
100 & 6.2 & 1.9 \\
1000 & 4.3 & -2.1 \\
10,000 & 4.0 & 4.5 \\
Inter-day $(n=18)$ & 6.7 & -4.2 \\
100 & 6.4 & 3.6 \\
1000 & 3.7 & \\
10,000 & 3.7 & \\
\hline
\end{tabular}

Intra- and inter-day precision (coefficient of variation $(\mathrm{CV} \%)$ ) and accuracy (expressed as bias\%) were evaluated using three points of QC samples. Six replicates of each point were assayed in one run for the intra-day experiment. Three replicates of each point of QC samples were assayed every day for six different days (inter-day experiment)

detected. This is likely because milder conditions were used in the current study.

Extracted/purified tacrolimus exhibited distinct characteristic peaks in XRD diffractogram and endothermic peak in DSC thermogram, suggesting the crystal nature of the drug. The melting point observed in our work was found to be $126^{\circ} \mathrm{C}$, which is identical to the melting point reported by Drug Bank database (http://www.drugbank.ca/
drugs/DB00864). Other investigators reported $126.6^{\circ} \mathrm{C}$ (13), $129^{\circ} \mathrm{C}(18)$, and $129.6^{\circ} \mathrm{C}$ (19) as melting point of tacrolimus. Overall, it could be concluded form DSC and XRD results that the powder of the extracted/purified tacrolimus is present in a crystalline state.

Tacrolimus is a known immunosuppressive agent commonly prescribed to organ transplant patients including the liver, kidney, heart, small bowel, pancreas, lung, skin,

a
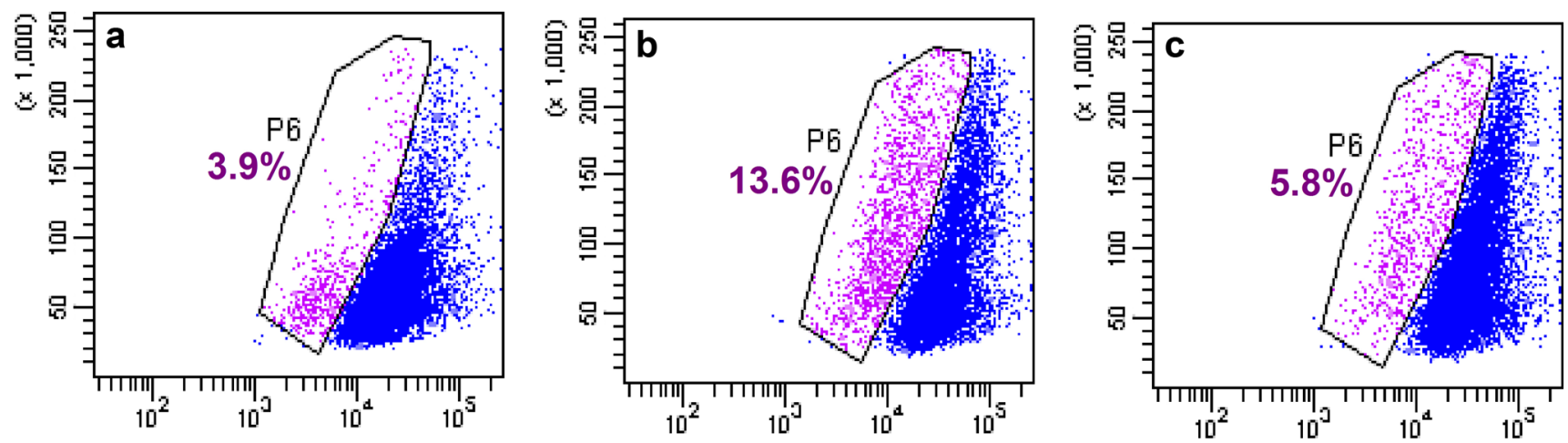

b
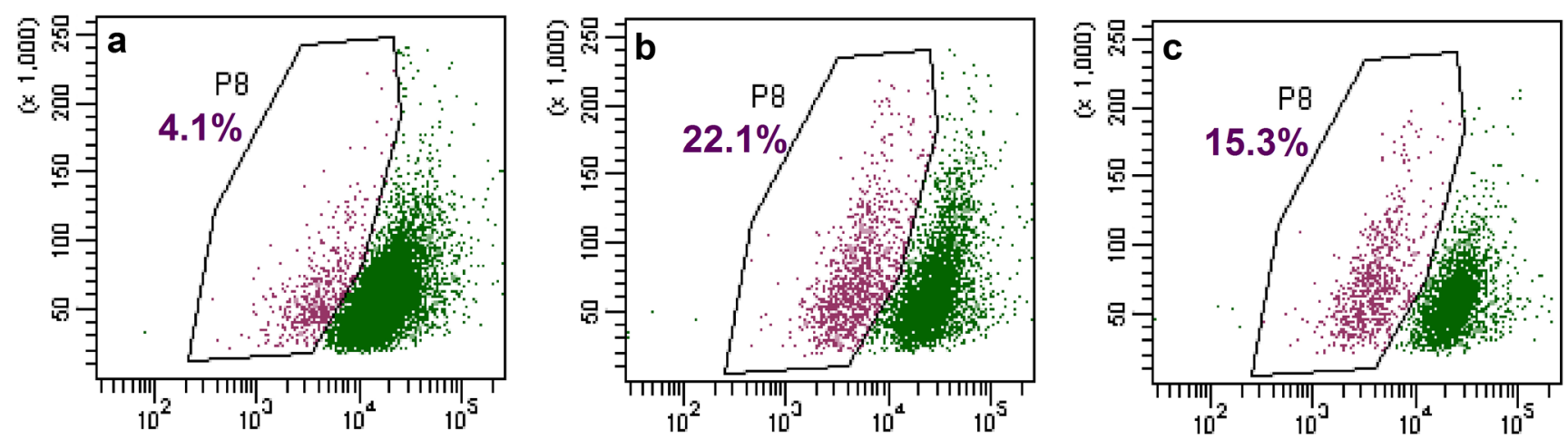

Fig. 5. Suppression of $\mathrm{T}$ cell proliferation by extracted/purified tacrolimus. Flow cytometric analysis was conducted on two cell groups: a CD4 ${ }^{+} \mathrm{T}$ cells and $\mathbf{b} \mathrm{CD}^{+} \mathrm{T}$ cells. For each cell group, dot-plot panels a representing $\mathrm{T}$ cell background physiological proliferation without any intervention (neither stimulation nor suppression), b representing $\mathrm{T}$ cells stimulated with concanavalin $\mathrm{A}$, and $\mathbf{c}$ representing $\mathrm{T}$ cells preincubated with extracted/purified tacrolimus and then stimulated with concanavalin A. For each panel, the $x$-axis represents fluorescence intensity and the $y$-axis represents cell count. CFSE dye was used to detect proliferating cells. As the cells divide, the dye is diluted, and hence, the more proliferating cells the less fluorescence intensity is detected. Gated populations ( $\mathrm{P} 6$ for $\mathrm{CD} 4^{+} \mathrm{T}$ cells group and $\mathrm{P} 8$ for CD8 ${ }^{+} \mathrm{T}$ cells group) represent the proliferating $\mathrm{T}$ lymphocytes. The percentage of proliferating $\mathrm{T}$ cells is presented next to each gate. All samples are composed of the same number of acquired events $\left(10^{6}\right.$ cells $)$ 


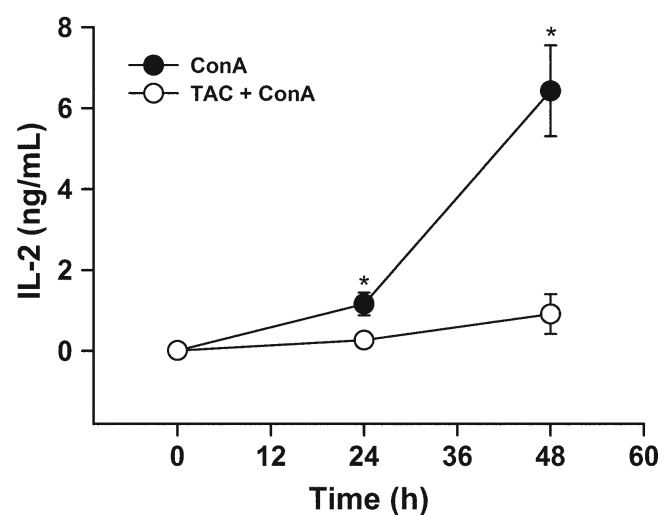

Fig. 6. IL-2 cytokine levels measured in PBMCs supernatants. Filled dots represent IL-2 protein levels secreted in the supernatant of PBMCs stimulated with concanavalin A (ConA), while unfilled dots represent IL-2 protein levels secreted in the supernatant of PBMCs pre-incubated with extracted/purified tacrolimus followed by stimulation with concanavalin A (TAC + ConA). IL-2 secretion was followed for 48 -h treatment. Data are presented are mean \pm SD of at three experiments. Statistical significance was indicated by an asterisk (*). Statistically significant inhibition was noticed after $24 \mathrm{~h}$

bone marrow, and limb transplants (20). The immunosuppressive action of tacroliums is mediated by calcineurin inhibition, which leads to the suppression of $\mathrm{T}$ cell proliferation and $\mathrm{T}$ cell activation (21-23). In our study, we explored whether tacrolimus retains the immunosuppressive effect after extraction and purification from expired Prograf ${ }^{\circ}$ capsules. Therefore, PBMCs were isolated from mice blood and incubated with extracted/purified tacrolimus as mentioned earlier. Subsequently, the suppressive effect of tacrolimus on cell proliferation was challenged with ConA. ConA is a lectin carbohydrate-binding protein that was originally extracted from the jack bean. It has been widely used as a mitogen to stimulate $\mathrm{T}$ cells. It acts by cross-linking $\mathrm{T}$ cell receptor leading to antigenindependent $\mathrm{T}$ cell proliferation (24). Tacrolimus

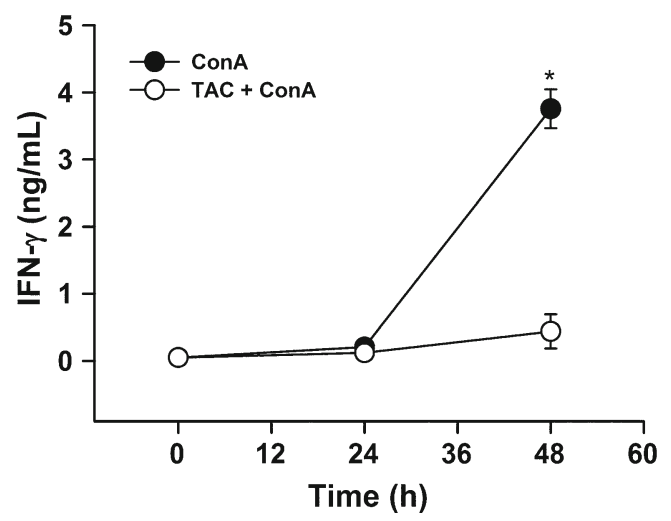

Fig. 7. IFN- $\gamma$ cytokine levels measured in PBMCs supernatants. Filled dots represent IFN- $\gamma$ protein levels secreted in the supernatant of PBMCs stimulated with concanavalin A (ConA), while unfilled dots represent IFN- $\gamma$ protein levels secreted in the supernatant of PBMCs pre-incubated with extracted/purified tacrolimus followed by stimulation with concanavalin A (TAC + ConA). IFN- $\gamma$ secretion was followed for 48 -h treatment. Data are presented are mean \pm SD of at three experiments. Statistical significance was indicated by an asterisk $(*)$. Statistically significant inhibition was noticed only after $48 \mathrm{~h}$ suppression of ConA-induced $\mathrm{T}$ cell proliferation was compared to unsuppressed PBMC group that was incubated with ConA alone.

We were able to demonstrate $\mathrm{T}$ cell suppression by the extracted/purified tacrolimus (Fig. 5). ConA ability to stimulate the proliferation of $\mathrm{CD}^{+}$and $\mathrm{CD}^{+} \mathrm{T}$ cells was remarkably suppressed following tacrolimus pre-incubation as compared to cells treated with ConA alone. Our results are consistent with the previous findings of Takama et al., who reported a significant suppression of $\mathrm{T}$ cell proliferation by allogenic mixed lymphocyte reaction in rat splenocytes following tacrolimus treatment (25). Moreover, tacrolimus was shown to reduce the amount of circulating $\mathrm{CD}^{+}$and $\mathrm{CD}^{+}$ $\mathrm{T}$ cells in treated mice (26). Nonetheless, we observed more profound suppressive effect of the extracted/purified tacrolimus on $\mathrm{CD}^{+}$cells (57.35\% suppression) as compared to $\mathrm{CD}^{+}$cells $(30.77 \%$ suppression). Knechtle and colleagues have reported consistent observation, where murine $\mathrm{T}$ cell proliferation was significantly suppressed in vivo for the $\mathrm{CD}^{+}$subset but not in the $\mathrm{CD} 8^{+}$subset (27). Similarly, Bishop and $\mathrm{Li}$ showed that tacrolimus exerts distinct in vivo effects, where $\mathrm{CD}^{+} \mathrm{T}$ cells are more sensitive than their $\mathrm{CD}^{+}$ counterparts (28). The reason behind this distinctive effect is still unclear to us; although, mechanistic studies have associated the suppressive effect of tacrolimus with the $\alpha \beta^{+} \mathrm{CD} 4^{+}$ subsets of $\mathrm{T}$ cells (29). Yet, further studies are needed to explain these observations, which are not in the scope of our current work.

Moreover, we proved the activity of our extracted/ purified tacrolimus by its ability to significantly decrease IL2 protein secretion from isolated PBMCs (Fig. 6). IL-2 is a critical cytokine for the maturation, proliferation, and differentiation of T cells (30). It is produced by stimulated T cells to act in autocrine and paracrine fashions $(31,32)$. Our extracted/ purified tacrolimus significantly inhibited ConA-stimulated secretion of IL-2. This is in agreement with the findings of Härtel et al., where IL-2 mRNA and protein levels in whole blood cells stimulated with anti-CD3/anti-CD28 were significantly reduced following tacrolimus pre-incubation (12). This clearly confirms the immunosuppressive activity of the extracted/purified tacrolimus as it was shown upon binding with FK506 binding protein (FKBP), the complex (FK506FKBP) has an ability to interact and inhibit calcineurin, resulting in the prevention of IL-2 production and $\mathrm{T}$ cell proliferation $(20,33)$.

Another direct evidence of the immunosuppressive activity of the extracted/purified tacrolimus is the significant suppression of IFN- $\gamma$ secretion by isolated PBMCs (Fig. 7). IFN- $\gamma$ is produced by multiple subsets of stimulated immune cells including natural killer (NK) cells, NKT cells, Th1 CD4 $4^{+}$cells, and $\mathrm{CD}^{+} \mathrm{T}$ cells (34). Therefore, the suppressive ability of extracted/purified tacrolimus on ConA-stimulated IFN- $\gamma$ secretion is evident of retained pharmacological functionality. Supportive evidence has been previously reported proving the inhibitory effect of tacrolimus on IFN- $\gamma$ production in human PBMC (35) as well as in murine model (36). This is consistent with our results. It is worth noting that IL-2 inhibition was noticed as early as $24 \mathrm{~h}$ in culture as compared to IFN-g, which required $48 \mathrm{~h}$ to show significance in inhibition. This is due to the kinetic difference in the production of the two cytokines where IFN-g secretion is slow (37) as compared to that of IL-2 (38). 


\section{CONCLUSIONS}

To address the question whether there is a quality difference between tacrolimus extracted and purified from expired capsules and reference drug, several analytical methods were employed. These tests assessed the quality and pharmacological activity of tacrolimus extracted/ purified from Prograf ${ }^{\circledR}$ capsules $(5 \mathrm{mg})$ that are beyond their expiration date. The data obtained showed no detectable difference in quality between the reference sample and extracted drug. Moreover, immunosuppressive activity of extracted/purified tacrolimus was evaluated on murine $\mathrm{T}$ cells by flow cytometric proliferation analysis and cytokines ELISA. The results showed that the extracted/purified tacrolimus was capable of suppressing the proliferation of stimulated $\mathrm{CD}^{+}$and $\mathrm{CD}^{+} \mathrm{T}$ cell subsets and significantly inhibited their secretion of IL-2 and IFN- $\gamma$ cytokines. Therefore, we concluded that the extracted/purified drug is suitable for reutilization in relevant experimental research. This is a rarely discussed matter although it carries a potential cost savings resulting from reutilization of API's from expired expensive medications especially when industrial reutilization is considered. Our results are concerned with tacrolimus as an individual API. Nonetheless, each API should undergo individual systematic evaluation.

\section{ACKNOWLEDGMENTS}

The authors are thankful to Ms. Roaa Al Kufeidi for her technical assistance. This project was funded by the National Plan for Science, Technology, and Innovation (MAARIFAH), King Abdulaziz City for Science and Technology, Kingdom of Saudi Arabia, award number 11-NAN1469-02.

\section{ELECTRONIC SUPPLEMENTARY MATERIAL}

Below is the link to the electronic supplementary material. High Resolution (TIFF 469 kb) High Resolution (TIFF $109 \mathrm{~kb}$ )

\section{REFERENCES}

1. Rath T. Tacrolimus in transplant rejection. Expert Opin Pharmacother. 2013;14(1):115-22. doi:10.1517/ 14656566.2013.751374.

2. Takeuchi S, Saeki H, Tokunaga S, Sugaya M, Ohmatsu H, Tsunemi Y, et al. A randomized, open-label, multicenter trial of topical tacrolimus for the treatment of pruritis in patients with atopic dermatitis. Ann Dermatol. 2012;24(2):144-50. doi:10.5021/ ad.2012.24.2.144.

3. De Simone C, Maiorino A, Tassone F, D'Agostino M, Caldarola G. Tacrolimus $0.1 \%$ ointment in nail psoriasis: a randomized controlled open-label study. J Eur Acad Dermatol Venereol. 2013;27(8):1003-6. doi:10.1111/j.1468-3083.2012.04642.x.

4. Udompataikul M, Boonsupthip P, Siriwattanagate R. Effectiveness of $0.1 \%$ topical tacrolimus in adult and children patients with vitiligo. J Dermatol. 2011;38(6):536-40. doi:10.1111/j.13468138.2010.01067.x.

5. Fruman DA, Klee CB, Bierer BE, Burakoff SJ. Calcineurin phosphatase activity in T lymphocytes is inhibited by FK 506 and cyclosporin A. Proc Natl Acad Sci U S A. 1992;89(9):3686-90.
6. Morales JM, Andres A, Dominguez-Gil B, Arriola M, Gutierrez MJ, Hernandez E, et al. Ten years of treatment with tacrolimus is related to an excellent renal function, allowing monotherapy in a large proportion of cases: unicentric results of the tacrolimus versus cyclosporine A European Multicentric Study in kidney transplant patients. Transplant Proc. 2005;37(9):3738-42. doi:10.1016/j.transproceed.2005.09.178.

7. Sigma-Aldrich. FK-506 monohydrate, $\geq 98 \%$ (HPLC). [01/09/ 2015]; Available from: http://www.sigmaaldrich.com/catalog/product/sigma/f4679?lang=en\&region=SA.

8. Sandford-Smith J. Outdated drugs may be useful. BMJ. 2003;326(7379):51.

9. Lyon RC, Taylor JS, Porter DA, Prasanna HR, Hussain AS. Stability profiles of drug products extended beyond labeled expiration dates. J Pharm Sci. 2006;95(7):1549-60. doi:10.1002/ jps.20636.

10. Boer TM, Marques MR, Cardoso SG. Determination of tacrolimus in pharmaceutical formulations by validated spectrophotometric methods. Revista de Ciências Farmacêuticas Básica e Aplicada. 2009.

11. FDA. Guidance for industry; bioanalytical method validation. Rockville: U.S. Department of Health and Human Services. 2001.

12. Hartel C, Schumacher N, Fricke L, Ebel B, Kirchner H, MullerSteinhardt M. Sensitivity of whole-blood T lymphocytes in individual patients to tacrolimus (FK 506): impact of interleukin-2 mRNA expression as surrogate measure of immunosuppressive effect. Clin Chem. 2004;50(1):141-51. doi:10.1373/ clinchem.2003.024950.

13. Ferraboschi P, Colombo D, De Mieri M, Grisenti P. Evaluation, synthesis and characterization of tacrolimus impurities. J Antibiot. 2012;65(7):349-54. doi:10.1038/ja.2012.28.

14. Boer TM, Procopio JV, Nascimento TG, Macedo RO. Correlation of thermal analysis and pyrolysis coupled to GC-MS in the characterization of tacrolimus. J Pharm Biomed Anal. 2013;73:18-23. doi:10.1016/j.jpba.2012.01.040.

15. Wu X, Hayes Jr D, Zwischenberger JB, Kuhn RJ, Mansour HM. Design and physicochemical characterization of advanced spray-dried tacrolimus multifunctional particles for inhalation. Drug Des Dev Ther. 2013;7:59-72. doi:10.2147/ DDDT.S40166.

16. Nakatsuka M, Ragan JA, Sammakia T, Smith DB, Uehling DE, Schreiber SL. Total synthesis of FK506 and an FKBP probe reagent, [C(8), C(9)-13C2]-FK506. J Am Chem Soc. 1990;112(14):5583-601. doi:10.1021/ja00170a024.

17. Mierke DF, Schmieder P, Karuso P, Kessler H. Conformational analysis of the cis- and trans-isomers of FK506 by NMR and molecular dynamics. Helv Chim Acta. 1991;74(5):1027-47. doi:10.1002/hlca.19910740513.

18. Patel P, Panchal S, Mehta T. Improvement of dissolution rate of tacrolimus by solid dispersion technique. J Pharmaceut Investig. 2013;43(1):45-53. doi:10.1007/s40005-013-0053-8.

19. Patel PV, Patel HK, Panchal SS, Mehta TA. Self microemulsifying drug delivery system of tacrolimus: formulation, in vitro evaluation and stability studies. Int $\mathrm{J}$ Pharmaceut Investig. 2013;3(2):95-104. doi:10.4103/2230-973X.114899.

20. Tanaka H, Nakahara K, Hatanaka H, Inamura N, Kuroda A. Discovery and development of a novel immunosuppressant, tacrolimus hydrate. Yakugaku Zasshi. 1997;117(8):542-54.

21. Yin M, Ochs RS. Mechanism for the paradoxical inhibition and stimulation of calcineurin by the immunosuppresive drug tacrolimus (FK506). Arch Biochem Biophys. 2003;419(2):207-13.

22. Halloran PF, Kung L, Noujaim J. Calcineurin and the biological effect of cyclosporine and tacrolimus. Transplant Proc. 1998;30(5):2167-70.

23. Tamura K, Fujimura T, Iwasaki K, Sakuma S, Fujitsu T, Nakamura K, et al. Interaction of tacrolimus(FK506) and its metabolites with FKBP and calcineurin. Biochem Biophys Res Commun. 1994;202(1):437-43.

24. Williams RM, Benacerraf B. Genetic control of thymus-derived cell function. I. In vitro DNA synthetic response of normal mouse spleen cells stimulated by the mitogens concanavalin A and phytohemagglutinin. J Exp Med. 1972;135(6):1279-92.

25. Takama Y, Miyagawa S, Yamamoto A, Firdawes S, Ueno T, Ihara $\mathrm{Y}$, et al. Effects of a calcineurin inhibitor, FK506, and a CCR5/CXCR3 antagonist, TAK-779, in a rat small intestinal 
transplantation model. Transpl Immunol. 2011;25(1):49-55. doi:10.1016/j.trim.2011.04.003.

26. Nichterlein T, Kretschmar M, Geginat G, Hirth K, Altenburg HP, Hof H. Effects of FK-506 on the course of murine salmonellosis. J Chemother. 1996;8(6):449-56. doi:10.1179/ joc.1996.8.6.449.

27. Hu H, Dong Y, Feng P, Fechner J, Hamawy M, Knechtle SJ. Effect of immunosuppressants on T-cell subsets observed in vivo using carboxy-fluorescein diacetate succinimidyl ester labeling. Transplantation. 2003;75(7):1075-7. doi:10.1097/ 01.TP.0000055832.35337.E6.

28. Bishop DK, Li W. Cyclosporin A and FK506 mediate differential effects on $\mathrm{T}$ cell activation in vivo. $\mathrm{J}$ Immunol. 1992;148(4):1049-54.

29. Salerno A, Bonanno CT, Caccamo N, Cigna D, Dominici R, Ferro C, et al. The effect of cyclosporin A, FK506 and rapamycin on the murine contact sensitivity reaction. Clin Exp Immunol. 1998;112(1):112-9.

30. Liao W, Lin JX, Leonard WJ. IL-2 family cytokines: new insights into the complex roles of IL-2 as a broad regulator of $\mathrm{T}$ helper cell differentiation. Curr Opin Immunol. 2011;23(5):598-604. doi:10.1016/j.coi.2011.08.003.

31. Williams MA, Tyznik AJ, Bevan MJ. Interleukin-2 signals during priming are required for secondary expansion of CD8+ memory T cells. Nature. 2006;441(7095):890-3. doi:10.1038/nature04790.

32. Feau S, Arens R, Togher S, Schoenberger SP. Autocrine IL-2 is required for secondary population expansion of $\mathrm{CD} 8(+)$ memory T cells. Nat Immunol. 2011;12(9):908-13. doi:10.1038/ni.2079.

33. Abou-Jaoude MM, Ghantous I, Almawi WY. Tacrolimus (FK506) versus cyclosporin A microemulsion (Neoral) maintenance immunosuppression: effects on graft survival and function, infection, and metabolic profile following kidney transplantation (KT). Mol Immunol. 2003;39(17-18):1095-100.

34. Schoenborn JR, Wilson CB. Regulation of interferon-gamma during innate and adaptive immune responses. Adv Immunol. 2007;96:41-101. doi:10.1016/S0065-2776(07)96002-2.

35. Kuinose M, Iwagaki H, Morimoto Y, Kohka H, Kobashi K, Sadamori $\mathrm{H}$, et al. Calcineurin antagonists inhibit interferongamma production by downregulation of interleukin-18 in human mixed lymphocyte reactions. Acta Med Okayama. 2000;54(5):201-9.

36. Zhang X, Han S, Kang Y, Guo M, Hong S, Liu F, et al. SAHA, an HDAC inhibitor, synergizes with tacrolimus to prevent murine cardiac allograft rejection. Cell Mol Immunol. 2012;9(5):390-8. doi:10.1038/cmi.2012.28.

37. Sadahiro A, Diogo CL, Oshiro TM, Shikanai-Yasuda MA Kinetics of IFN-gamma, TNF-alpha, IL-10 and IL-4 production by mononuclear cells stimulated with gp43 peptides, in patients cured of paracoccidioidomycosis. Rev Soc Bras Med Trop. 2007;40(2):156-62.

38. Carlsson R, Sjogren HO. Kinetics of IL-2 and interferongamma production, expression of IL-2 receptors, and cell proliferation in human mononuclear cells exposed to staphylococcal enterotoxin A. Cell Immunol. 1985;96(1):175-83. 